\title{
Twitter and Facebook Usage for Academic Motivation Among Post-Graduate Students in Lahore, Pakistan
}

\author{
Umair Shahzad $^{1,2}$, Ahmad Bilal ${ }^{3,4}$ \\ ${ }^{1}$ Department of Mass Communication Management, The Superior College Lahore, Lahore, Pakistan \\ ${ }^{2}$ Department of Mass Communication, Forman Christian College (A Chartered University), Lahore, Pakistan \\ ${ }^{3}$ College of Art \& Design, University of the Punjab Lahore, Lahore, Pakistan \\ ${ }^{4}$ School of Art \& Design, Nottingham Trent University, Nottingham, UK \\ Email address: \\ purpleresearchfeedback@gmail.com (U. Shahzad), ahmad.bilal2010@my.ntu.ac.uk (A. Bilal)
}

\section{To cite this article:}

Umair Shahzad, Ahmad Bilal. Twitter and Facebook Usage for Academic Motivation Among Post-Graduate Students in Lahore, Pakistan. International and Public Affairs. Vol. 3, No. 1, 2019, pp. 20-24. doi: 10.11648/j.ipa.20190301.14

Received: July 1, 2019; Accepted: July 23, 2019; Published: August 10, 2019

\begin{abstract}
The use of social networking sites is spreading globally. It is seen in present world that these social media tools are being used as academic media tools too. Students share their assignments-oriented information on Facebook pages. Students communicate among themselves regarding class schedules on Twitter by Tweets. The researcher also found out that the students involve their course instructors on these kinds of platforms too. After that the researcher decided to work on a question that are these tools academically motivating students or not? This research analyzed the link between academic motivation and post-graduate students via Twitter and Facebook in educational institutions that combines a social media forum for the students to share their educational involvement with each other for the enhancement of their knowledge, improvement in their academic assignments and receiving motivation for doing academic work. The study was conducted to add in the field of academic research. Mass Communication Management students were selected as respondents because they have much knowledge of communication tools either print, electronic or internet including social media tools, and they can more critically evaluate the benefits or flaws of communication advancements. The theoretical framework for this study was uses and gratifications theory. The approach was quantitative. The research showed that Twitter has slightly less role in academic motivation but Facebook has a very effective role in academic motivation in Lahore Pakistan.
\end{abstract}

Keywords: Uses and Gratifications, Facebook, Twitter, Academic Motivation, Post-Graduate Student, Study Gratifications, Academic Globe

\section{Introduction}

Social media is a diverse network. The use of social networking sites in Pakistani educational institutions can be effective because of its ability to provide many options of sharing among people for instance messages, photos, videos, calls, documents, animations, locations, status etc. Since the launch of Facebook and Twitter in 2006 there have been some electronic communication reforms in the world that has led to the shift of social communication via telecommunication services to internet oriented social media. This has resulted in a large number of social networking sites users in the world. The use of Facebook and twitter is increasing rapidly, in Pakistan too.
While Facebook and Twitter are being used for social community another community is seen very active on these social networking sites and that is the student community of Pakistan. This research analyzed the use of Facebook and Twitter on post-graduate students for academic motivation in educational institutions that structures a social media forum for the students to share their educational involvement with each other for the enhancement of their knowledge, improvement in their academic assignments and receiving motivation for doing academic work.

\subsection{Objectives of the Study}

1. To find out if Twitter can be an additional tool that facilitates academic motivation among post-graduate 
students in Lahore, Pakistan

2. To investigate if Facebook can be an additional tool that facilitates academic motivation among post-graduate students in Lahore, Pakistan.

\subsection{Significance of the Study}

This research will be helpful in identifying the significance of Facebook and Twitter in academic motivation on the postgraduate students.

It can change the concept of people that even Twitter and Facebook have a role in the academic activities of students.

\subsection{Theoretical Frame Work}

"Uses and gratifications approach" simply represents an attempt to explain something of the way in which individuals use communications, among other resources in their environment, to fill their needs and to achieve their goals [5].

The theory uses and gratification is effective in understanding motivations and needs for using the internet [2].

\subsection{Hypotheses}

The below hypotheses were proposed:

$\mathrm{H}_{1}$ : There is statistically significant relationship between Facebook usage and academic motivation among postgraduate students.

$\mathrm{H}_{2}$ : There is statistically significant relationship between Twitter usage and academic motivation among post-graduate students.

\subsection{Literature Review}

The previous literature indicates many different researches on social media usage even in the context of academics. Educators must know about digital tools because these networks provide ideas and information to bring back to professional communities as schools [9].

The research evidence lacks regarding the social media usage patterns among post-graduate students specifically in Pakistan that generates this gap.

Therefore, the theory of uses and gratifications is applicable for a study of social networking sites, but requires expanding and retesting [6].

Social media tools are often called academic media tools of resources for people to explore for education [4].

There are many social media usage patterns because an individual person has his own requirements for using something but the researcher chose academic motivation as a usage pattern for the pilot study because the researcher wanted to get a view of the benefits of Facebook and Twitter for motivation of students towards studies.

Facebook has the potential of being used as a learning Management System in educational institutions and because of the accessibility the students get while using it in both learning and non-learning scenarios [1].

Twitter usage, is has vital role in learning process of university students and it is viable and viewed as a motivating experience for them [11].
The Latest Educational environments demand from the academic institutes to provide sufficient knowledge-based structures to assist access to education, learning, information and knowledge sources through new technologies, internet, applications, electronic communication devices and social networking sites as Facebook and Twitter [7].

Use of social media in particular Twitter and Facebook from the mobile applications is having significant impact in the classroom both towards students and instructors so it is recommended that social media should be used in teaching practices in the classrooms [14].

Twitter is highly accepted by students for the progress of their academic activities [15].

Students involving in teacher education come with experience and practice of new educational ways covering the social networks as twitter but it is seen that students do not use such mediums for knowledge but only for communication [16].

\section{Method}

The approach for the study was quantitative research. The mass media research domain was uses and user for academic research. The method was paper and pencil questionnaire. The tool for data collection was closed-ended questionnaire. According to SPSS Survival Manual Cronbach alpha coefficient of a scale should be above 0.7 [13].

In this research the Cronbach alpha coefficient for a tool used to measure Twitter and Facebook Usage for Academic Motivation among Post-Graduate Scale was 0.701. The data was analyzed by interpretive approach by making tables and graphs. The study has implications for the academic and educational institutions for using the social media tools in an effective way.

The data was collected after identification of the target population for the appropriate results of the pilot study. In Pakistan there are approximately 43.90 million numbers of Pakistani social media accounts reported as of 15 February 2017, according to the statistics released by social media companies and majority of accounts belong to Facebook that are 29.99 million, after that Twitter 2.99 million and after that the remaining [10].

So, the pilot study was conducted with specifying Facebook and Twitter so that relevant data can be collected but other option was mentioned in the questionnaire to check how many users had accounts other than Facebook and Twitter. As these accounts include post-graduate students too so further for sample collection post-graduate students were selected. Convenient sampling technique was employed to select the target sample for a pilot study because population was diverse and list of population was not present.

Units of analysis were the post-graduate students of Mass Communication Management. The sample size consisted of $40[n=40]$ from the weekend programs from the department of M. Phil. Mass communication management of The Superior Group of Colleges Lahore. The number of respondents was selected by using sample size calculator from the website 
"https://www.surveysystem.com/sscalc.htm" by selecting 12.8 percent confidence interval, 95 percent confidence level for approximately 120 of population size of the post-graduate students belonging to mass communication management of selected institution. These were selected because they belong to the scenario of weekend programs so these respondents have more experience to use social networking sites when they are not meeting physically with their class fellows, instructors and educational institution's administration for a long period of time in a week and the logic behind selecting the mass communication management students for the pilot study was opted from a research article that stated a survey conducted on a sample of New Zealand journalism or mass communication students it was seen that vast majority of them are active on social networking sites such that 83.9 percent of the males and 98.6 percent of the female respondents have a Facebook page and 41.9 percent of the males and 52.7 percent of the female respondents have been active on Facebook for more than two years [3].

\section{Results}

According to the responses 60 percent use Facebook, 20 percent use Twitter and remaining 20 percent use other social networking sites. There was a relationship between social networking sites usage and academic motivation towards mass communication management post-graduate students. It was investigated using Pearson product-moment correlation coefficient. It was seen that there is a positive correlation between the two variables $[r=0.311, n=40, p>0.0005]$, with normal levels of interconnectedness between social networking sites usage and academic motivation and continuous influences on the respondents.

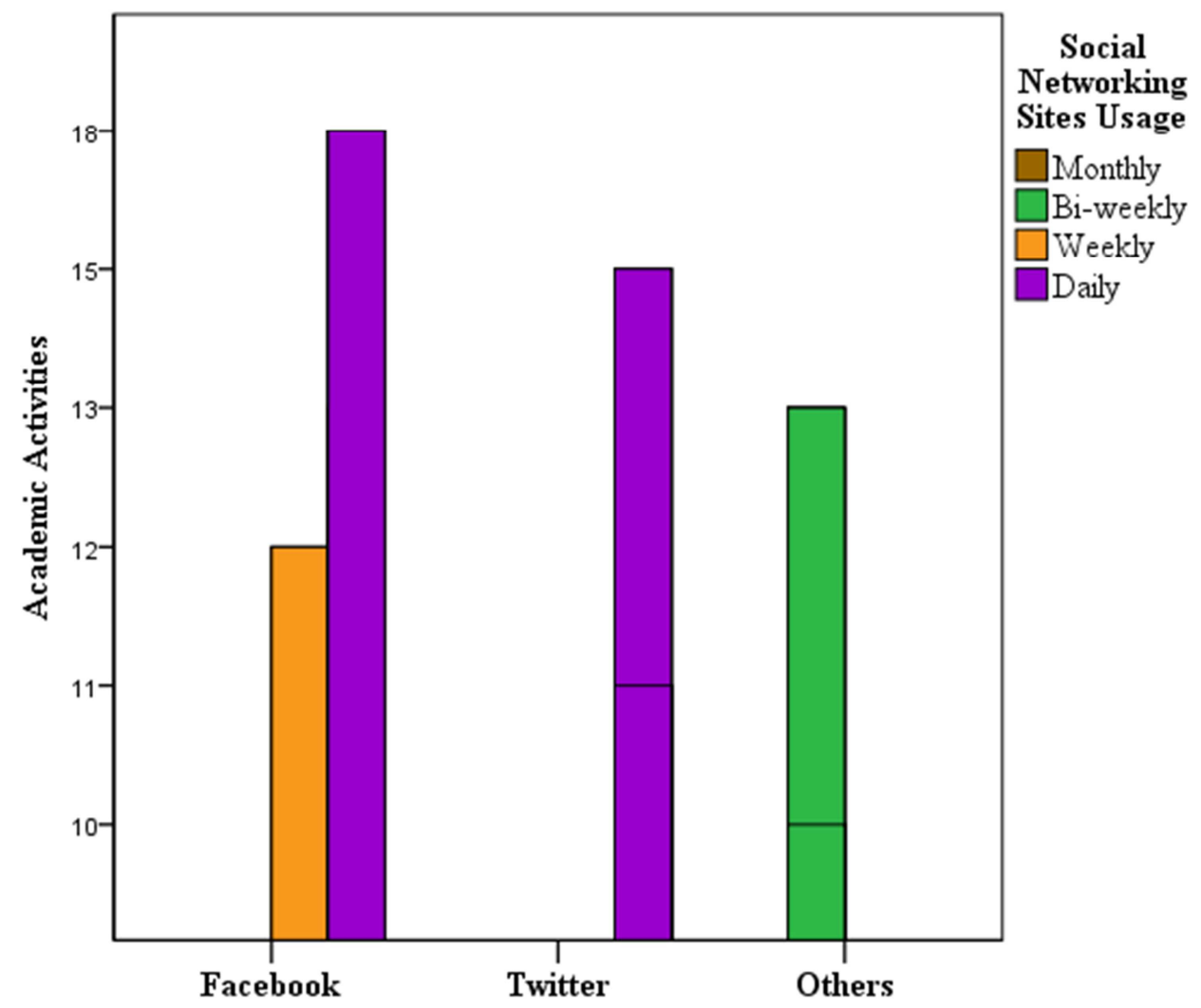

Figure 1. Clustered bar graph of the academic motivation level of post-graduate students, their social networking sites preferences and usage.

Facebook is being used much in the educational institutions by a similar sample, category and scenario for the number of students using social network communities on internet conducted on the college campus of The University of North Carolina at Chapel Hill in state North Carolina USA on $\mathrm{N}=38$ respondents consisting of under-graduate and graduate professional students indicated that 90 percent of the under-graduate use Facebook [12].

As the average showed that majority of the respondents admit Facebook as a tool for academic motivation so our H1 was accepted but Twitter and other SNS have very little ability in this scenario. Details are mentioned in the below figure 1 for reader's information.

\section{Discussion}

As mentioned in introduction, the purpose of this study was to examine the relationship between Facebook or Twitter usage and academic motivation of post-graduate students. 40 students participated in the study by completing single closed-ended questionnaire survey. The primary limitation of this study was convenient sampling technique and small sample size out of the target population. One more limitation of this study was a specific academic institute 
located in Lahore, Pakistan because according to the scenario of this research a specific institute was selected that had weekend study program where physical academic motivation is less because the students only visit their institute once in a while. And actually, social media was the main source that was connecting those students. In the present study, it was outside the scope to control other variables that might had contributed to an increase or decrease in student academic motivation. It is significant to note that Facebook and Twitter are few of many tools used for online social networking. These websites themselves are continuously evolving as the online socialization shapes itself whereas the users continue to utilize these websites. Therefore, the conclusions of this study should be viewed within the broader context of the online examples of social media usage of post-graduate students. The conclusions of this study contribute to the literature detailing the role of social networking sites as Facebook and Twitter for academic motivation in the lives of students.

\section{Conclusions}

This study showed that Facebook is a major tool in motivating post-graduate students toward academics. Uses and gratification theory is accepted in the setting of Lahore Pakistan towards post-graduate students specifically from mass communication. Therefore, $\mathrm{H}_{1}$ was accepted widely instead of $\mathrm{H}_{2}$ as Twitter has a very minute significance towards academic motivation.

The research conclusion was then checked with other research repositories to see if any other researches indicated the use of Facebook for academic motivation in any way so according to the results of a study on 133 undergraduate students, it was seen after conducting one-way ANOVA to compare scores between the high self-disclosure and low self-disclosure conditions. There was a significant difference between those participants who viewed the Facebook of a teacher high in self-disclosure had higher levels of motivation and effective learning than participants who viewed the Facebook website of a teacher low in self-disclosure [8].

The author via understanding this research has come to a conclusion that this world is turning much more towards an Academic Globe where people residing in any other country are having education from any other country's academic institute without physically going there by virtual means. And even the present technology is connecting academic sector with social virtual means.

The figure 2 shows "SNS Academic Motivation Model." It analyzes the academic motivation of mass communication post-graduate students in relation to Facebook, Twitter and other social networking sites.

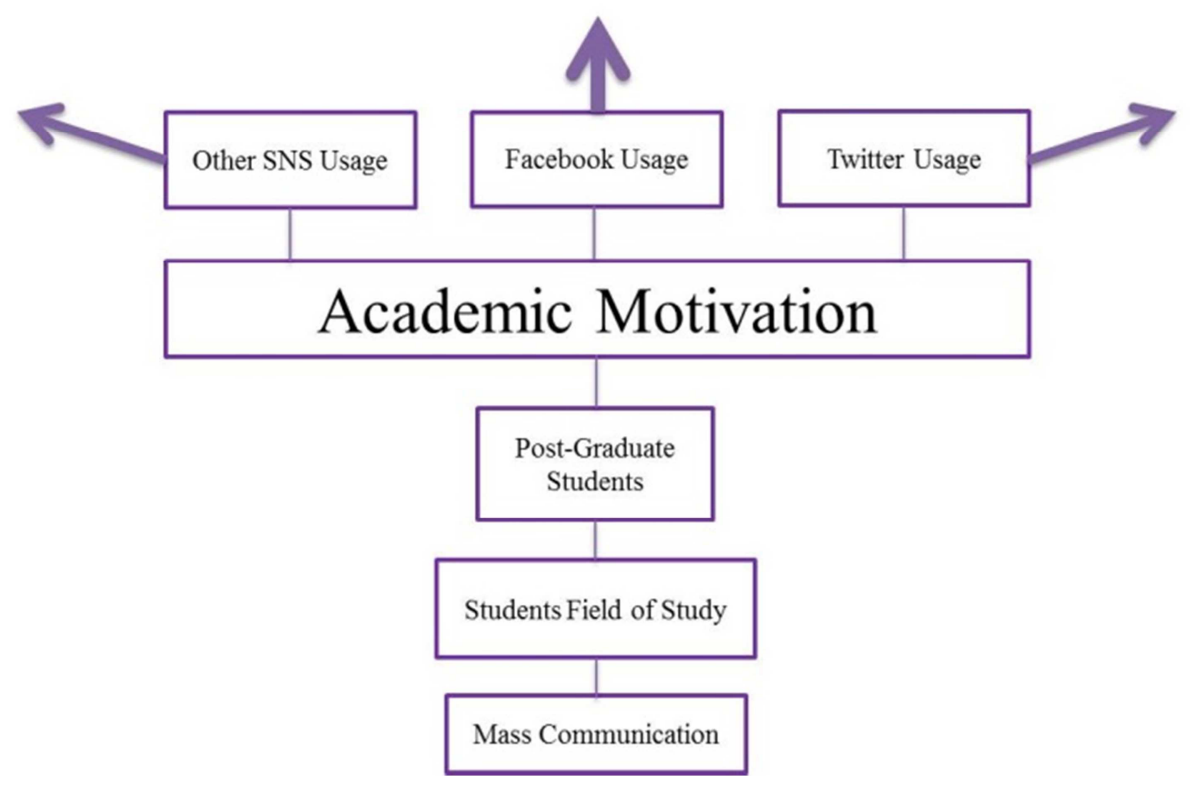

Figure 2. "SNS Academic Motivation Model" for the crux of this research.

This study has implications for research on international students. The social networking sites usage is a very longlasting and complex area of study. It is required to investigate how the use of these sites can assist more in this world that is turning in an "Academic Globe" by conducting bigger researches so that the SNS tools usage for study gratifications can be identified. Social Media Study Gratifications are the needs of students that are being filled by social media sites. In this way actual benefits of SNS can be introduced. While the trends are changing from physical academics to virtual academics. Therefore, it is significant to find out what are the advantages or flaws of having education from actual physical means or virtual social means. The critical side of future academics should be verified.

\section{Dedication and Acknowledgements}

This research article is dedicated to a peaceful country Pakistan. Love for knowledge never dies if a lover knows the importance of knowledge. This research article is generated 
with the satisfactory efforts of the Instructor Dr. Ahmed Bilal, the student Umair Shahzad and those who were involved in this research including respondents etc. This quantitative research is written for academic cause and it is for awareness among researchers.

\section{References}

[1] Eli, M., \& Gilad, R. (2015). Facebook Groups as an Academic Teaching Aid: Case Study and Recommendations for Educators. Journal of Educational Technology \& Society, 18 (4), 371-384.

[2] Hanjun, K., Chang-Hoan, C., \& Marilyn, S. R. (2005). Internet Uses and Gratifications: A Structural Equation Model of Interactive Advertising. Journal of Advertising, 34 (2), 57-70.

[3] Hirst, M., \& Treadwell, G. (2011). Blogs bother me: Social media, journalism students and the curriculum. Journalism Practice, 5 (4), 446-461.

[4] Hoffman, D. (2011, 2011 May-June). The social media scene in education.Internet@Schools,6.

[5] Katz, E., Blumler, J. G., \& Gurevitch, M. (1973). Uses and Gratifications Research. The Public Opinion Quarterly, 37 (4), 509-523.

[6] Lineberry, Z. X. (2012). Uses and gratifications on social networking sites: Analysis of use and value of social networking sites for three types of social capital on college students. Iowa State University.

[7] Makori, E. O. M. N. O. (2016). DIGITAL TECHNOLOGY ACCEPTANCE IN TRANSFORMATION OF UNIVERSITY LIBRARIES AND HIGHER EDUCATION INSTITUTIONS IN KENYA. University of Nebraska - Lincoln.

[8] Mazer, J. P., Murphy, R. E., \& Simonds, C. J. (2007). I'll see you on "Facebook": The effects of computer-mediated teacher self-disclosure on student motivation, affective learning, and classroom climate. Communication Education, $56(1), 1-17$.

[9] Nussbaum-Beach, S. (2012). JUST THE FACTS: PERSONAL LEARNING NETWORKS. Educational Horizons, 91 (2), 26-27.

[10] Phoneworld. (2017). Over 43.90 million social media accounts in Pakistan. Retrieved October 14, 2017, from www. ThePhoneworld.com.

[11] Ricoy, M.-C., \& Tiberio, F. (2016). Twitter as a Learning Community in Higher Education. Journal of Educational Technology \& Society, 19 (1), 237-248.
[12] Stutzman, F. (2006). An evaluation of identity-sharing behavior in social network communities. Journal of the International Digital Media and Arts Association, 3 (1), 10-18.

[13] Pallant, J. (2004). SPSS survival manual: a step by step guide to data analysis using SPSS for Windows. Buckingham: Open University Press.

[14] Cochrane, T., Sissons, H., Mulrennan, D., \& Pamatatau, R. (2013). Journalism 2.0: Exploring the Impact of Mobile and Social Media on Journalism Education. International Journal of Mobile and Blended Learning, 5.

[15] Wang, T., Wang, F., \& Shi, L. (2013). The use of microblog-based case studies in a pharmacotherapy introduction class in China. BMC Medical Education, 13 (1), 120.

[16] Faltis, C. J. (2013). Introduction\&\#x2014; New Literacies, Teacher Quality, and Data-Based Program Improvement. Teacher Education Quarterly, 40 (3), 3-5.

\section{Biography}

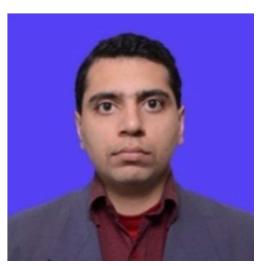

Umair Shahzad He did his M. Phil. Mass Communication Management with exceptional thesis in the field of social media and academics from The Superior College Lahore. He did his graduation in B.A. (Hons.) major in Mass Communication from Forman Christian College (A Chartered University) Lahore, Punjab, Pakistan. His major research affiliations are mass communication, education, computer science, health, STEM, universe, peace and academics. The researcher aims to induct research essence in most of the population of Pakistan so that the country can prosper and become successful in future. The author is strongly determined to work for peace in his country and represent his country as a peaceful land to live in.

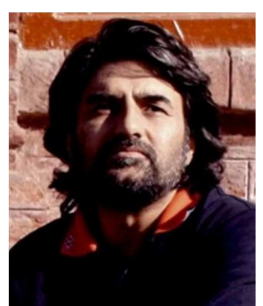

Ahmad Bilal, He did his $\mathrm{PhD}$ in Film and Television from School of Art \& Design, Nottingham Trent University UK. He is a scholarship holder for MA leading to $\mathrm{PhD}$ from UK. He is a Silver Medallist in MFA Graphic Designing from University of the Punjab. His major research affiliations are technology, new media, film and documentary production, academics, globalization and advertising. 